\title{
Traction strategy with clips and rubber band allows complete en bloc endoscopic submucosal dissection of sessile serrated adenoma/polyp invading the site of previous appendectomy
}

Endoscopic submucosal dissection (ESD) is now the reference method for en bloc resection of colorectal neoplasia with fibrosis [1]. Nevertheless, ESD appears difficult when the lesion develops on the site of previous appendectomy with severe submucosal fibrosis, and surgery was the only option before the introduction of the full-thickness resection device [2]. However, clip and rubber band traction completely changed the ESD procedure by offering triangulation to reveal the submucosal cutting line, even in cases of submucosal fibrosis or when the lesion deeply invaded the appendix [3]. We report here the case of a 60 -year-old woman with a history of appendectomy in childhood who underwent a colonoscopy that revealed a sessile serrated lesion on the appendectomy scar.

After delineation of the margins, we performed the ESD procedure as follow

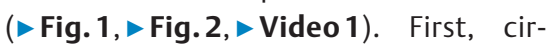
cumferential incision and deep trimming were performed following injection. Then, submucosal dissection of the proximal side was performed to create a mucosal flap to allow the positioning of the traction system. The first clip with rubber band was attached to the mucosal flap and a second clip grasped the rubber band and was attached to the opposite side of the cecum. Once attached, the submucosal space, although fibrotic, appeared, and dissection into the fibrotic tissue became feasible.
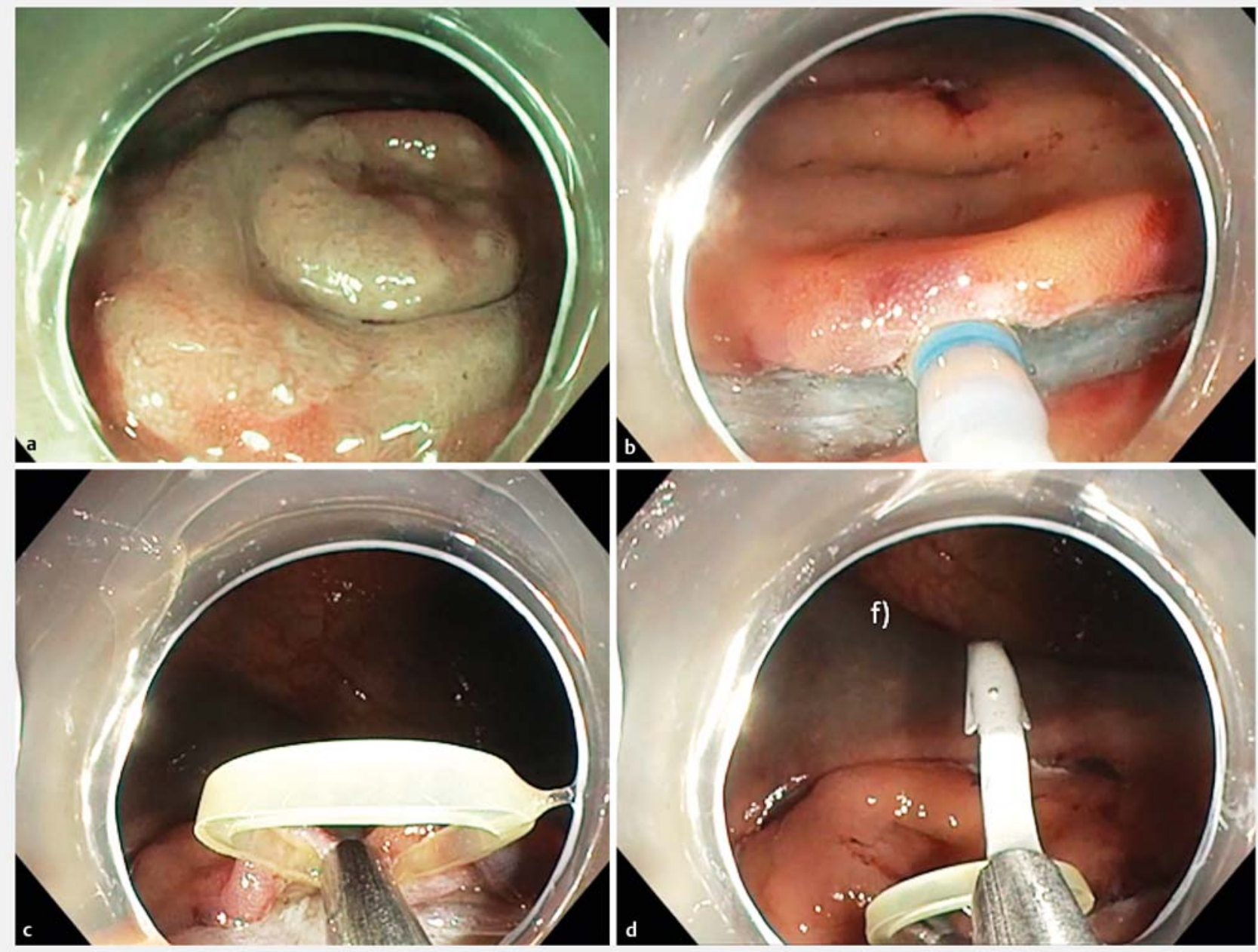

- Fig. 1 Clip and rubber band strategy to achieve resection of a sessile serrated lesion on the site of previous appendectomy. a The lesion at the appendectomy site. $\mathbf{b}$ Incision and trimming on the oral side. $\mathbf{c}$ Attachment of the first clip. $\mathbf{d}$ Second clip traction. 


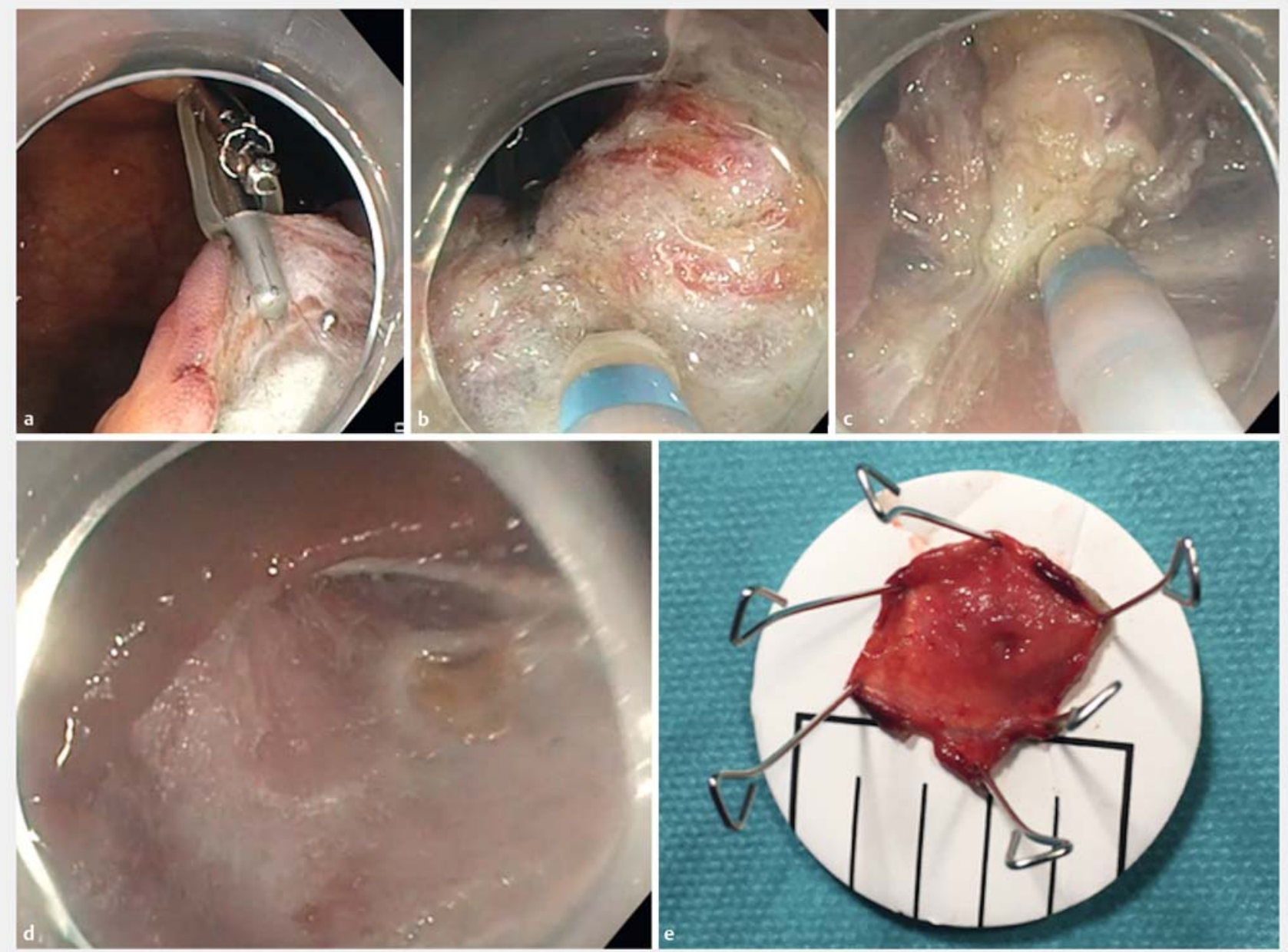

- Fig. 2 End of dissection and management of the resected area. a Traction system. b Performing endoscopic submucosal dissection under traction. $\mathbf{c}$ End of dissection in the sclerolipomatosis tissue of the previous appendectomy. $\mathbf{d}$ Resected area. e Specimen stretched onto cork.

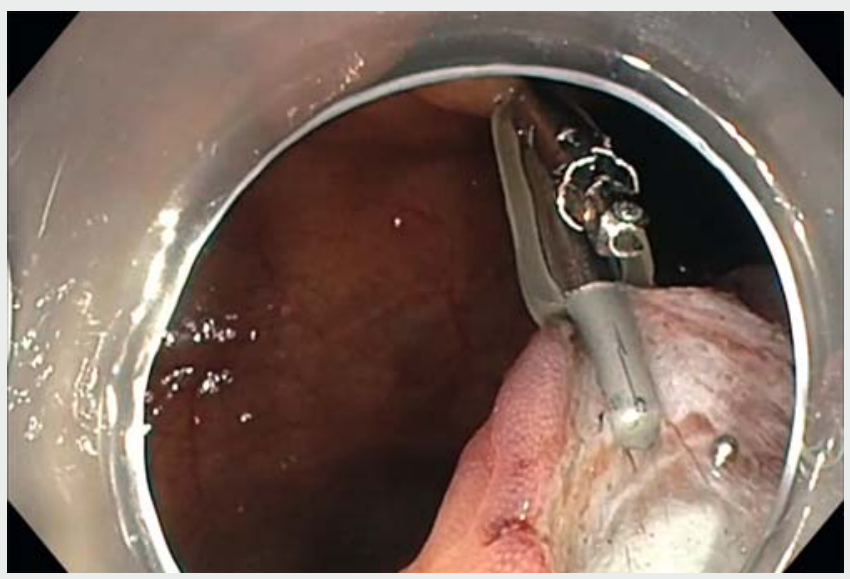

$\checkmark$ Video 1 Clip and rubber band strategy to achieve resection of a sessile serrated lesion on the site of previous appendectomy.
Resection was achieved in less than 20 minutes thanks to the traction, and no perforation occurred through the fibrotic wall. A clip was fixed from the appendectomy orifice to a small incision in the distant mucosa to cover the defect in order to prevent delayed perforation. The resection was en bloc and R0, and the patient was discharged 1 day later. ESD with clip and rubber band traction is a helpful technique, which allows ESD to be performed in this difficult situation thanks to the triangulated traction.

Endoscopy_UCTN_Code_TTT_1AQ_2AD

\section{Competing interests}

None 
The authors

Borathchakra Oung', Edouard Chabrun 2,3, Clément Subtil $^{2,3}$, Elodie Cesbron-Metivier ${ }^{3,4}$, Véronique Dumora-Ezponda ${ }^{5}$, Jérémie Jacques $^{3,6}$, Mathieu Pioche ${ }^{1,3}$

1 Department of Endoscopy and Gastroenterology, Pavillon L, Edouard Herriot Hospital, Lyon, France

2 Department of Endoscopy and Gastroenterology, Bordeaux University Hospital, Bordeaux, France

3 French Society of Digestive Endoscopy (SFED), France

4 Department of Endoscopy and Gastroenterology, Angers University Hospital, Angers, France

5 Department of Gastroenterology, Private Clinic, Biarritz, France

6 Department of Endoscopy and Gastroenterology, Dupuytren University Hospital, Limoges, France
Corresponding author

\section{Mathieu Pioche, MD}

Endoscopy Unit - Digestive Disease

Department, Pavillon L - Edouard Herriot

Hospital, 69437 Lyon Cedex, France

Fax: +33-4-72110147

mathieu.pioche@chu-lyon.fr

\section{References}

[1] Rahmi G, Tanaka S, Ohara Y et al. Efficacy of endoscopic submucosal dissection for residual or recurrent superficial colorectal tumors after endoscopic mucosal resection. J Dig Dis 2015; 16: 14-21

[2] Lupu A, Jacques ], Rivory J et al. Hybrid endoscopic submucosal dissection using a full-thickness resection device allows en bloc resection of a large adenoma deeply invading the appendix. Endoscopy 2018; 50 : E296-E298

[3] Utzeri E, Jacques ], Charissoux A et al. Traction strategy with clips and rubber band allows complete en bloc endoscopic submucosal dissection of laterally spreading tumors invading the appendix. Endoscopy 2017; 49: 820-822

\section{Bibliography}

DOI https://doi.org/10.1055/a-0868-7792

Published online: 1.4.2019

Endoscopy 2019; 51: E166-E168

(c) Georg Thieme Verlag KC

Stuttgart · New York

ISSN 0013-726X

\section{ENDOSCOPY E-VIDEOS}

https://eref.thieme.de/e-videos

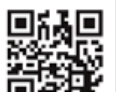

Endoscopy E-Videos is a free

然: access online section, reporting on interesting cases and new

techniques in gastroenterological endoscopy. All papers include a high quality video and all contributions are freely accessible online.

This section has its own submission website at https://mc.manuscriptcentral.com/e-videos 